\title{
The effectiveness and cost effectiveness of dark chocolate consumption as prevention therapy in people at high risk of cardiovascular disease: best case scenario analysis using a Markov model
}

\author{
(c) $\frac{(1)(8)}{\text { gy }}$ OPEN ACCESS
}

\author{
Ella Zomer PhD student ${ }^{1}$, Alice Owen senior research fellow ${ }^{1}$, Dianna J Magliano senior research \\ fellow $^{2}$, Danny Liew professor ${ }^{3}$, Christopher M Reid professor ${ }^{1}$
}

${ }^{1}$ CCRE Therapeutics, Department of Epidemiology and Preventive Medicine, Monash University, The Alfred Centre, Melbourne, Victoria, Australia; ${ }^{2}$ Baker IDI Heart and Diabetes Institute, Melbourne; ${ }^{3}$ Melbourne EpiCentre, Department of Medicine, University of Melbourne, Royal Melbourne Hospital, Melbourne

\begin{abstract}
Objective To model the long term effectiveness and cost effectiveness of daily dark chocolate consumption in a population with metabolic syndrome at high risk of cardiovascular disease.

Design Best case scenario analysis using a Markov model.

Setting Australian Diabetes, Obesity and Lifestyle study.

Participants 2013 people with hypertension who met the criteria for metabolic syndrome, with no history of cardiovascular disease and not receiving antihypertensive therapy.

Main outcome measures Treatment effects associated with dark chocolate consumption derived from published meta-analyses were used to determine the absolute number of cardiovascular events with and without treatment. Costs associated with cardiovascular events and treatments were applied to determine the potential amount of funding required for dark chocolate therapy to be considered cost effective.

Results Daily consumption of dark chocolate (polyphenol content equivalent to $100 \mathrm{~g}$ of dark chocolate) can reduce cardiovascular events by $85(95 \%$ confidence interval 60 to 105$)$ per 10000 population treated over 10 years. $\$ A 40$ ( $225 ; € 31 ; \$ 42$ ) could be cost effectively spent per person per year on prevention strategies using dark chocolate. These results assume $100 \%$ compliance and represent a best case scenario.

Conclusions The blood pressure and cholesterol lowering effects of dark chocolate consumption are beneficial in the prevention of cardiovascular events in a population with metabolic syndrome. Daily dark chocolate consumption could be an effective cardiovascular preventive strategy in this population.
\end{abstract}

\section{Introduction}

Cardiovascular disease is the leading cause of death worldwide, with the death rate estimated at 17.5 million in 2004 (29\% of all deaths). ${ }^{1}$ The metabolic syndrome describes a cluster of risk factors that significantly increase the risk of developing cardiovascular disease and diabetes, ${ }^{2}$ and the syndrome is becoming increasingly prevalent owing to rising rates of obesity and diabetes and an aging population. Lifestyle changes such as dietary modifications and behavioural adaptations constitute first line treatment in the prevention of diseases associated with the metabolic syndrome. Dietary modifications that increase the intake of vegetables, fruit, and grains and decrease the intake of saturated fats and refined sugars are recommended. It is believed that the high content of polyphenolic antioxidants in some fruit, vegetables, whole grains, nuts, and tea may contribute to their cardioprotective effects. ${ }^{3}$ Dark chocolate, derived from cocoa beans, is another food rich in polyphenols, specifically flavonoids. Flavonoids exhibit antihypertensive, anti-inflammatory, antithrombotic, and metabolic effects, all of which may contribute to their protective effect. ${ }^{4}$

Several recent studies have suggested that the consumption of dark chocolate may have blood pressure lowering effects. ${ }^{56}$ The mechanisms for these effects remain under investigation, but flavanols have been shown to stimulate the production of endothelial nitric oxide, causing blood vessels to dilate and thus lowering blood pressure. ${ }^{78} \mathrm{~A}$ recent meta-analysis showed that a diet high in cocoa rich products significantly reduced blood pressure in both hypertensive and prehypertensive states. Studies exploring the effect of dark chocolate on blood pressure thus far have been relatively short, with a maximum intervention period of 18 weeks in the studies contributing to a recent meta-analysis. ${ }^{10}$

Dark chocolate consumption has also been suggested to have lipid modifying effects, decreasing total and low density lipoprotein cholesterol levels and increasing high density 
lipoprotein cholesterol levels. ${ }^{11}$ However, these changes have also only been explored in short term trials, lasting 2-18 weeks. The logistical difficulties and considerable expense of long term placebo controlled clinical trials of dietary components mean it is unlikely that high level evidence linked to cardiovascular disease outcome will be obtained in the near future. We utilised available data and statistical modelling techniques to estimate the long term effects and associated cost effectiveness, from a healthcare system perspective, of dark chocolate consumption in a population with metabolic syndrome at high risk of cardiovascular disease.

\section{Methods}

We constructed a Markov model ${ }^{12}$ to assess the health effects and associated costs of daily consumption of plain dark chocolate compared with no chocolate in a population with metabolic syndrome without diabetes and initially without cardiovascular disease. The figure $\Downarrow$ depicts the health states included in the model: "alive without cardiovascular disease," "alive with cardiovascular disease," "dead from cardiovascular disease," and "dead from other causes." We used decision analysis ${ }^{13}$ to compare two health strategies: no dark chocolate (control) with dark chocolate (treatment). The perspective adopted was that of the Australian healthcare system.

All individuals entered the model in the initial health state of being alive without cardiovascular disease. With each annual cycle, we used risk prediction algorithms and population life tables to determine the probability of an individual transitioning to the other health states - that is, developing non-fatal cardiovascular disease or dying from cardiovascular disease or non-cardiovascular causes. All events were assumed to occur half way through a cycle. Individuals continued to cycle through the model, with more and more moving into diseased or dead states as the period of follow-up increased, until the period of interest (10 years) was reached or death occurred.

In any cycle, we generated random numbers of between 0 and 1.0 to determine if any event occurred. For example, the 100th person in our model was a 44 year old, non-smoking male, whose baseline characteristics were: systolic blood pressure 143 $\mathrm{mm} \mathrm{Hg}$, total cholesterol concentration $7.0 \mathrm{mmol} / \mathrm{L}$, high density lipoprotein cholesterol concentration $1.0 \mathrm{mmol} / \mathrm{L}$, glycated haemoglobin $\left(\mathrm{HbA}_{1 \mathrm{c}}\right) 32.2 \mathrm{mmol} / \mathrm{mol}$, body mass index 33.9, and absence of diabetes. In the first cycle (year 1), his probability of a non-fatal cardiovascular event was $0.27 \%$, fatal cardiovascular event was $0.006 \%$, and non-cardiovascular fatal event was $0.15 \%$. The random number generated for this man in cycle 1 was 0.046 . He was therefore assumed to have experienced a non-fatal cardiovascular event and was subsequently moved to the health state of being alive with cardiovascular disease for the start of cycle 2 . Had the random number been between 0.27 and $0.27+0.006 \%$, he would have been assumed to have experienced a fatal cardiovascular event and moved to the health state of dead from cardiovascular disease. Had the random number been between $0.27+0.006 \%$ and $0.27+0.006 \%+0.15 \%$, he would have been assumed to have experienced a non-cardiovascular fatal event and moved to the health state of dead from other causes. Had the random number been greater than $0.27+0.006 \%+0.15 \%$, he would have been assumed to have survived the cycle without a cardiovascular event and been returned to the health state of being alive without cardiovascular disease.

\section{Modelled population and subject data}

The population used in the model comprised participants selected from the Australian Diabetes Obesity and Lifestyle (AusDiab) study, among whom cardiovascular risk was estimated individually. Detailed descriptions of the Australian Diabetes, Obesity and Lifestyle study have been published elsewhere. ${ }^{14}$ Only participants free of cardiovascular disease or diabetes, or both, at baseline, and classified as having metabolic syndrome according to the joint interim guidelines ${ }^{15}$ (published in 2009) were included in the model. The joint interim guidelines define metabolic syndrome on the basis of three of five risk factors: increased waist circumference with population specific and country specific definitions; triglyceride concentrations $\geq 150 \mathrm{mg} / \mathrm{dL}(1.7 \mathrm{mmol} / \mathrm{L})$ or drug treatment for increased triglyceride levels; high density lipoprotein cholesterol concentration $<40 \mathrm{mg} / \mathrm{dL}(1.0 \mathrm{mmol} / \mathrm{L})$ in males and $<50 \mathrm{mg} / \mathrm{dL}$ $(1.3 \mathrm{mmol} / \mathrm{L})$ in females, or drug treatment for reduced high density lipoprotein cholesterol levels; systolic blood pressure $\geq 130 \mathrm{~mm} \mathrm{Hg}$ or diastolic blood pressure $\geq 85 \mathrm{~mm} \mathrm{Hg}$ or both, or treatment for hypertension; and fasting glucose concentration $\geq 100 \mathrm{mg} / \mathrm{dL}$ or drug treatment for increased glucose levels. We also excluded those who were receiving antihypertensive therapy.

\section{Risks of cardiovascular disease and death}

We used Framingham algorithms ${ }^{16}$ to calculate the baseline risk of non-fatal cardiovascular disease, comprising myocardial infarction and stroke, as well as cardiovascular death. These risks were calculated according to individual specific data on age, sex, systolic blood pressure, total cholesterol level, high density lipoprotein cholesterol level, smoking status, presence or absence of diabetes, and presence or absence of left ventricular hypertrophy. With each annual cycle we recalculated cardiovascular risk according to increases in age and expected changes in systolic blood pressure, total cholesterol level, and high density lipoprotein cholesterol level. Age and sex specific changes to blood pressure and lipid levels were determined according to baseline data stratified by sex and five year age bands. From these we derived annual changes within age bands. We assumed all changes to be linear.

We calculated the risk of death among people with cardiovascular disease using one year mortality data from the Reduction of Atherothrombosis for Continued Health (REACH) registry. ${ }^{17}$ This prospective cohort study followed people with at least three atherothrombotic risk factors or a history of atherothrombotic disease, or both, for a period of two years, collecting data on morbidity and mortality. As mortality data from the Reduction of Atherothrombosis for Continued Health registry were not specified for subgroups, we made the assumption that all people with cardiovascular disease shared the same risks of death.

We calculated the risks of dying from non-cardiovascular causes using national long term, age and sex specific mortality data from Australia. ${ }^{18}$ The most recent available data were from 2007. Owing to lack of data stratified by history of cardiovascular disease, we made the assumption that the data were the same for participants with and without cardiovascular disease.

\section{Treatment benefit}

Changes in cardiovascular risk associated with the treatment arm were calculated by application of expected effects of dark chocolate on systolic blood pressure and lipid levels. Data on the blood pressure lowering effects of dark chocolate consumption were gathered from a meta-analysis of 13 
randomised controlled trials studying the effect of chocolate or cocoa on blood pressure. ${ }^{9}$ All trials were longer than 14 days but heterogeneous for levels of flavonoids (range 30-1008 $\mathrm{mg} /$ day) administered in various forms (table $\Downarrow$ ). This meta-analysis found that cocoa products rich in flavonols, such as dark chocolate, had a blood pressure lowering effect compared with the control (systolic blood pressure $-3.2 \mathrm{~mm}$ $\mathrm{Hg}, 95 \%$ confidence interval -5.1 to $-1.2 \mathrm{~mm} \mathrm{Hg}, \mathrm{P}=0.001$; diastolic blood pressure $-2.0 \mathrm{~mm} \mathrm{Hg},-3.4$ to $-0.7 \mathrm{~mm} \mathrm{Hg}$, $\mathrm{P}=0.003$ ). When participants were stratified according to hypertension, blood pressure was significantly reduced in those with hypertension (systolic blood pressure $-5.0 \mathrm{~mm} \mathrm{Hg},-8.0$ to $-2.1 \mathrm{~mm} \mathrm{Hg}, \mathrm{P}<0.001$; diastolic blood pressure $-2.7 \mathrm{~mm}$ $\mathrm{Hg},-4.9$ to $-0.6 \mathrm{~mm} \mathrm{Hg}, \mathrm{P}=0.01$ ), but not significantly reduced in those in a normotensive state (systolic blood pressure -1.6 $\mathrm{mm} \mathrm{Hg},-3.8$ to $0.7 \mathrm{~mm} \mathrm{Hg}, \mathrm{P}=0.17$; diastolic blood pressure $-1.3 \mathrm{~mm} \mathrm{Hg},-2.9$ to $0.3 \mathrm{~mm} \mathrm{Hg}, \mathrm{P}=0.12$ ). Some heterogeneity existed among the treatment effects observed between trials (systolic blood pressure $\mathrm{I}^{2}=74 \%$; diastolic blood pressure $\left.\mathrm{I}^{2}=62 \%\right)$. This remained high in the hypertensive subgroup $\left(\mathrm{I}^{2}=90 \% ; \mathrm{I}^{2}=79 \%\right)$ but was reduced in the normotensive state $\left(I^{2}=23 \% ; I^{2}=24 \%\right)$.

Effects of dark chocolate consumption on lipid profiles were informed by a meta-analysis of eight short term trials investigating the effect of cocoa on healthy participants (table 1). ${ }^{11}$ It showed that short term (2-18 weeks) consumption of dark chocolate decreased low density lipoprotein cholesterol concentrations $(-0.15 \mathrm{mmol} / \mathrm{L}, 95 \%$ confidence interval -0.29 to $-0.02 \mathrm{mmol} / \mathrm{L}, \mathrm{P}=0.03$ ) but had no significant effect on total cholesterol concentrations $(-0.15 \mathrm{mmol} / \mathrm{L},-0.32$ to 0.02 $\mathrm{mmol} / \mathrm{L}, \mathrm{P}=0.08$ ) or high density lipoprotein cholesterol concentration $(0.03 \mathrm{mmol} / \mathrm{L},-0.07$ to $0.13 \mathrm{mmol} / \mathrm{L}, \mathrm{P}=0.56)$. Subgroup analyses according to health status, however, showed that dark chocolate consumption could significantly reduce both total cholesterol and low density lipoprotein cholesterol levels in those with high cardiovascular risk (total cholesterol 0.21 $\mathrm{mmol} / \mathrm{L}, 95 \%$ confidence interval -0.35 to $-0.06 \mathrm{mmol} / \mathrm{L}$, $\mathrm{P}=0.007$; low density lipoprotein cholesterol $-0.20 \mathrm{mmol} / \mathrm{L}$, -0.38 to $-0.01 \mathrm{mmol} / \mathrm{L}, \mathrm{P}=0.04)$. In subgroup analyses, high density lipoprotein cholesterol levels did not change significantly.

Table $2 \Downarrow$ summarises the treatment effects assumed in the model.

\section{Costs}

Costs of cardiovascular events were taken from a review on the cost of cardiovascular complications in a "healthy" population. ${ }^{19}$ They are summarised in table 2. Costs included direct costs of myocardial infarction and stroke, measured for the first year of the event and after the first year. We took the cost of a fatal cardiovascular event from an economic analysis of chronic diseases in Australia. ${ }^{20}$

All costs were inflated to reflect 2012 costs according to the Australian national health price index. ${ }^{21}$

\section{Outcome measures}

The outcomes of interest were number of events prevented, number of life years saved, and potential monies available for prevention strategies provided the incremental cost effectiveness ratios met arbitrary thresholds, in terms of Australian dollars per year of life saved. We calculated the number of deaths prevented, by determining the difference in number of deaths between those consuming and not consuming dark chocolate. Similarly, we calculated the years of life saved by determining the number of life years gained from dark chocolate consumption compared without.

We calculated incremental cost effectiveness ratios by comparing the difference in net costs between treatment (a diet rich in cocoa products) and no treatment (control), divided by the difference in years of life lived by each cohort. The time horizon of the modelled analysis was 10 years.

All future benefits (years of life lived) and costs were discounted at $5 \%$ per annum..$^{22}$ All analyses were also done using compliance levels of $80 \%, 90 \%$, and $100 \%$.

\section{Probabilistic sensitivity analyses}

Probabilistic sensitivity analyses ${ }^{23}$ were undertaken using $95 \%$ confidence intervals surrounding the point estimates for blood pressure lowering effect and lipid change and $10 \%$ uniform distributions around cost inputs. We assessed the effects of the uncertainty surrounding point estimates simultaneously by 1000 iterations of Monte Carlo simulation. ${ }^{24}$ Table 2 outlines the uncertainty ranges applied to key model inputs.

\section{Results}

Overall, 3069 participants (27.3\%) from the Australian Diabetes, Obesity and Lifestyle study were classified as having metabolic syndrome according to the joint interim statement for metabolic syndrome published in 2009, and free of diagnosed cardiovascular disease or frank diabetes. Of these, 1056 (34.4\%) were receiving antihypertensive therapy or had systolic blood pressures below $121 \mathrm{~mm} \mathrm{Hg}$. With these excluded, a total of 2013 (65.6\%) participants were included in our model. Table $3 \Downarrow$ summarises the characteristics of the modelled population. The cohort was relatively young, with a mean age of 53.6 years. Because this was a high risk population and selected for hypertension, the cohort had increased blood pressure (mean systolic blood pressure $141.1 \mathrm{~mm} \mathrm{Hg}$ ), cholesterol levels (mean total cholesterol $6.1 \mathrm{mmol} / \mathrm{L}$ ), glucose levels (mean $\mathrm{HbA}_{1 \mathrm{c}} 34.4$ $\mathrm{mmol} / \mathrm{mol}$ ), and waist circumference (mean $100.4 \mathrm{~cm}$ ).

Table $4 \Downarrow$ summarises the results of the base case and probabilistic sensitivity analyses. With $100 \%$ compliance, dark chocolate consumption could potentially prevent 70 non-fatal (interquartile range 55-85) and 15 fatal (5-20) cardiovascular events per 10000 population treated over 10 years. The estimated incremental cost effectiveness ratio was $\$ A 50000$ ( $£ 31$ 150; $€ 38555 ; \$ 52500$ ) per years of life saved when $\$ A 40$ (interquartile range $\$ A 29-55 ; \$ 42, \$ 31-58$ ) per person per year was assumed to have been spent on a prevention strategy using dark chocolate.

When compliance levels were reduced from $100 \%$ (best case) to $90 \%$, the number of non-fatal and fatal events potentially preventable was reduced to 60 (interquartile range 50-80) and $10(5-20)$ per 10000 population treated over 10 years, respectively. When compliance levels were further reduced to $80 \%$, the equivalent figures were 55 (40-70) and 10 (5-20). The potential monies available for prevention strategies per person for the incremental cost effectiveness ratios to be considered cost effective were estimated at \$A37 (interquartile range \$A26-51; \$39, \$27-54) when 90\% of individuals complied with dark chocolate consumption and \$A32 (\$A22-45; \$34, \$23-47) when $80 \%$ complied.

\section{Discussion}

Daily consumption of dark chocolate for 10 years in a population with metabolic syndrome that was free of diabetes and cardiovascular disease at baseline and classified as being 
prehypertensive or hypertensive, would be effective in the prevention of cardiovascular events. The blood pressure and cholesterol lowering properties associated with dark chocolate consumption could potentially prevent 70 (interquartile range 55-85) non-fatal (defined as non-fatal stroke and non-fatal myocardial infarction) cardiovascular events and 15 (5-20) cardiovascular related deaths per 10000 population treated over 10 years. To our knowledge this is the first study to model the long term effects of dark chocolate consumption in reducing cardiovascular risk.

Assuming that \$A40 (\$42) is spent per person per year on a dark chocolate prevention strategy in this population, the strategy would be cost effective (based on the commonly accepted, albeit arbitrary, threshold of $\$ 50000$ per years of life saved $^{25}$ ). The $\$ A 40$ per person per year could be devoted to advertising, educational campaigns, or potentially subsidisation of dark chocolate in this high risk population.

Analyses of lower compliance levels indicated that although the number of preventable non-fatal and fatal cardiovascular events would be reduced, the incremental cost effectiveness ratios remained below accepted cost effective thresholds. Therefore, even if only $80 \%$ of individuals with metabolic syndrome were compliant with the daily consumption of dark chocolate over 10 years, it could still be considered an effective and cost effective intervention strategy.

Only non-fatal stroke and non-fatal myocardial infarction were explored in this analysis, and the potential effectiveness of dark chocolate consumption on other cardiovascular events, such as heart failure, were not assessed. It is also important to note that the cardiovascular protective effects of cocoa, and more specifically flavonoids, have only been shown for dark chocolate, rather than for milk or white chocolate. This is possibly a result of higher levels of flavonoids in dark chocolate and an inhibitory effect in the absorption of flavonoids found in the milk varieties as a result of interactions of milk proteins. ${ }^{26}$ Therefore any effects shown in this analysis pertain specifically to dark chocolate (or equivalent amounts of cocoa or polyphenol enriched chocolate).

\section{Comparison with other studies}

The effects of dark chocolate consumption on blood pressure and total cholesterol, although beneficial, are not as profound as those of drug interventions. A meta-analysis ${ }^{27}$ found that blood pressure lowering drugs can reduce systolic blood pressure by $9.1 \mathrm{~mm} \mathrm{Hg}$ at a standard dose and $7.1 \mathrm{~mm} \mathrm{Hg}$ at a half dose. The Statin Therapies for Elevated Lipid Levels compared Across doses to Rosuvastatin (STELLAR) trial ${ }^{28}$ estimated that statins (at a dose of $20 \mathrm{mg} /$ day) could reduce total cholesterol concentrations to between 1.20 and $2.64 \mathrm{mmol} / \mathrm{L}$. Despite the lower efficacy of dark chocolate consumption, short term clinical trials thus far have shown low (if any) adverse events and high rates of compliance. The blood pressure lowering and total cholesterol lowering effects of dark chocolate consumption provide a non-drug treatment option, either alone or in combination with therapeutic interventions.

\section{Limitations of the study}

A few limitations to our analyses warrant mention. Firstly, no algorithm for risk prediction of cardiovascular events in a population with metabolic syndrome is available. The Framingham algorithm was developed from a healthy 20th century cohort and therefore may under-predict events in a higher risk population. Other available algorithms for higher risk populations, such as those of the United Kingdom
Prospective Diabetes Study (intended specifically for use in people with diabetes), may conversely over-predict risk. The Framingham algorithm was chosen for the present analyses as it was likely to represent a conservative estimate of the effects of dark chocolate consumption.

A second limitation pertained to the estimations of risk of death after a non-fatal cardiovascular event. Owing to limitations in the availability of subgroup specific data, we assumed the risks of dying from both cardiovascular and non-cardiovascular causes to be the same for all those with established cardiovascular disease. We also assumed that the risk of dying from non-cardiovascular related causes was the same for those with cardiovascular disease as without. This is of course not accurate, as risk of dying is influenced not only by the type and severity of the initial non-fatal event but also by other risk factors that may increase mortality risk. The likely consequence was an underestimation of risk of death among those with cardiovascular disease, and again reflected our erring on the side of conservatism.

We did not consider several other effects of dark chocolate. On the one hand, dark chocolate or cocoa polyphenols have been shown to generate beneficial metabolic effects (including decreased low density lipoprotein cholesterol levels, ${ }^{29}$ increased high density lipoprotein cholesterol levels, ${ }^{30}$ and increased insulin sensitivity ${ }^{31}$ ); improve endothelial function and cause anti-inflammatory and antithrombotic effects ${ }^{32}{ }^{33}$; reduce stress ${ }^{34}$; and improve mood. ${ }^{35}$ Conversely, dark chocolate contains sugar and imposes an additional caloric and glycaemic load ${ }^{32}$ that may need to be accounted for by modification of the background diet to reduce the risk of weight gain (as usually occurs in dietary intervention studies). While in many cases this could be achieved through substitution of chocolate for other snack foods in the diet, we were not able to account for other dietary changes in the modelling analyses. However, recent studies have found that dark chocolate also increases satiety, ${ }^{33}$ potentially countering the additional caloric and carbohydrate load imposed by the dark chocolate.

A further limitation to our analyses was the assumption that the benefits of dark chocolate, observed in short term trials, extended to 10 years. This assumption is common in any long term therapy, including drug treatment. Heterogeneity among treatment effects was also noted, owing to one trial in the meta-analysis being a statistical outlier. We excluded this study in a revised meta-analysis (which improved homogeneity), and derived a systolic blood pressure reducing effect of $-3.0 \mathrm{~mm}$ $\mathrm{Hg}(95 \%$ confidence interval -4.31 to $-2.38 \mathrm{~mm} \mathrm{Hg})$. When applied to the model, the revised potential monies available for prevention was only marginally decreased, to \$A32 (interquartile range \$A21-43; \$34, \$22-45).

Finally, it is acknowledged that the present analysis assumed compliance rates with dark chocolate ranging from $80 \%$ to $100 \%$. The studies contributing to the recent meta-analysis ${ }^{911}$ reported no side effects and also optimal compliance. However, one study noted that $20 \%$ of participants did not consider dark chocolate to be an acceptable long term treatment option. ${ }^{36}$

\section{Conclusions and implications of study findings}

The findings of this study suggest that the blood pressure lowering and lipid effects of plain dark chocolate could represent an effective and cost effective strategy for the prevention of cardiovascular disease in people with metabolic syndrome (and no diabetes). Chocolate benefits from being by and large a pleasant, and hence sustainable, treatment option. Evidence to 
date suggests that the chocolate would need to be dark and of at least $60-70 \%$ cocoa, or formulated to be enriched with polyphenols.

We thank the Australian Diabetes, Obesity and Lifestyle study steering committee for providing data from the Australian Diabetes, Obesity and Lifestyle study.

Contributors: EZ developed epidemiological model and carried out statistical analysis and drafted the manuscript. AO participated in the design of the model and revised the manuscript. DJM participated in data and subject selection and revised the manuscript. DL assisted in development of the epidemiological model and revised the manuscript. CMR participated in the design of the model and revised the manuscript. All authors read and approved the final manuscript.

Funding: This research was supported by an Australian Research Council linkage grant (LP0775329) with Sanofi-Aventis Australia. Competing interests: All authors have completed the ICMJE uniform disclosure form at www.icmje.org/coi_disclosure.pdf (available on request from the corresponding author) and declare: no support from any organisation for the submitted work; no financial relationships with any organisations that might have an interest in the submitted work in the previous three years; and no other relationships or activities that could appear to have influenced the submitted work.

Ethical approval: This study was approved by Monash University's human ethics committee utilising research involving existing data.

Data sharing: requests for access to data should be made to the corresponding author (Chris.Reid@monash.edu).

1 World Health Organization. Cardiovascular diseases: fact sheet No 317. WHO, 2007.

2 Wilson PW, D'Agostino RB, Parise H, Sullivan L, Meigs JB. Metabolic syndrome as a precursor of cardiovascular disease and type 2 diabetes mellitus. Circulation 2005;112:3066-72

3 Fraga CG, Litterio MC, Prince PD, Calabro V, Piotrkowski B, Galleano M. Cocoa flavanols: effects on vascular nitric oxide and blood pressure. J Clin Biochem Nutr 2011;48:63-7.

4 Lippi G, Franchini M, Montagnana M, Favaloro EJ, Guidi GC, Targher G. Dark chocolate: consumption for pleasure or therapy? J Throm Thrombolysis 2009;28:482-8.

5 Egan BM, Laken MA, Donovan JL, Woolson RF. Does dark chocolate have a role in the prevention and management of hypertension? Commentary on the evidence. Hypertension 2010:55:1289-95.

6 Taubert D, Roesen R, Lehmann C, Jung N, Schomig E. Effects of low habitual cocoa intake on blood pressure and bioactive nitric oxide: a randomized controlled trial. JAMA 2007;298:49-60.

7 Hollenberg NK, Schmitz H, Macdonald I, Poulter N. Cocoa, flavanols and cardiovascular risk. Br J Cardiol 2004;11;379-86.

8 Fisher NDL, Hughes M, Gerhard-Herman M, Hollenberg NK. Flavanol-rich cocoa induces nitric-oxide dependent vasodilation in healthy humans. J Hypertens 2003;21:2281-6.

9 Ried K, Sullivan T, Fakler P, Frank OR, Stocks NP. Does chocolate reduce blood pressure? A meta-analysis. BMC Med 2010;8:39.

10 Taubert D, Roesen R, Schomig E. Effect of cocoa and tea intake on blood pressure: a meta-analysis. Arch Intern Med 2007;167:626-34.

11 Jia L, Liu X, Bai YY, Li SH, Sun K, He C, et al. Short-term effects of cocoa product consumption on lipid profile: a meta-analysis of randomized control trials. Am J Clin Nutr 2010;92:218-25

12 Sun X, Faunce T. Decision-analytical modelling in health-care economic evaluations. Eur $J$ Health Econ 2008:9:313-23.

13 Petrou S, Gray A. Economic evaluation using decision analytical modelling: design conduct, analysis and reporting. BMJ 2011;342:d1766.

14 Dunstan DW, Zimmet PZ, Welborn TA, Cameron AJ, Shaw J, de Courten M, et al; Australian Diabetes, Obesity and Lifestyle Study (AusDiab). The Australian Diabetes, Obesity and Lifestyle Study (AusDiab)—-methods and response rates. Diabetes Res Clin Pract 2002;57:119-29.

15 Alberti KGMM, Eckel RH, Grundy SM, Zimmet PZ, Cleeman JI, Donato KA, et al. Harmonizing the metabolic syndrome: a joint interim statement of the International Diabetes
Federation Task Force on Epidemiology and Prevention; National Heart, Lung, and Blood Institute; American Heart Association; World Heart Federation; International Atherosclerosis Society; and International Association for the Study of Obesity. Circulation 2009;120:1640-5.

16 Anderson KM, Odell PM, Wilson PW, Kannel WB. Cardiovascular disease risk profiles. Am Heart J 1991;121(1 Pt 2):293-8.

17 Ohman EM, Bhatt DL, Steg PG, et al for the REACH Registry Investigators. The Reduction of Atherothrombosis for Continued Health (REACH) Registry: an international, prospective, observational investigation in subjects at risk for atherothrombotic events-study design. Am Heart J 2006;295:180-9.

18 Australian Institute of Health and Welfare 2011. National GRIM books. AlHW, 2011 www. aihw.gov.au/national-grim-books.

19 Salkeld G, Phongsavan P, Oldenberg B, Johannesson M, Convery P, Granham-Clarke $\mathrm{P}$, et al. The cost-effectiveness of a cardiovascular risk reduction program in general practice. Health Policy 1997;41:105-19.

20 Walker A, Butler JR. Economic model system of chronic diseases in Australia: a novel approach initially focusing on diabetes and cardiovascular disease. Int J Simul Process Model 2010;6:137-51.

21 Huynh T. Convenience care: a patient-centered mode duling. Phys Exec 2004;30:56-8

22 Severens IL, Milne RJ. Discounting health outcomes in economic evaluation: the ongoing debate. Value Health 2004;7:397-401.

23 O'Hagen A, McCabe C, Akehurst R, Brennan A, Briggs A, Claxton K, et al. Incorporation of uncertainty in health economic modelling studies. Pharamacoeconomics 2005;26:529-36.

24 Sonnenberg FA, Beck JR. Markov models in medical decision making: a practical guide. Med Decis Making 1993:13:322-38.

25 Li R, Zhang P, Barker LE, Chowdhury FM, Zhang X. Cost-effectiveness of interventions to prevent and control diabetes mellitus: a systematic review. Diabet Care 2010;33:1872-94

26 Serafini M, Bugianesi R, Maiani G, Valtuena S, De Santis S, Crozier A. Plasma antioxidants from chocolate. Nature 2003;424:1013.

27 Law MR, Wald NJ, Morris JK, Jordan RE. Value of low dose combination treatment with blood pressure lowering drugs: analysis of 354 randomised trials. BMJ 2003:326:1427-35.

28 Jones PH, Davidson MH, Stein EA, Bays HE, McKenney JM, Miller E, et al; STELLAR Study Group. Comparison of the efficacy and safety of rosuvastatin versus atorvastatin, simvastatin and pravastatin across doses (STELLAR ${ }^{*}$ Trial). Am J Cardiol 2003;92:152-60.

29 Jia L, Liu X, Bai YY, Li SH, Sun K, He C, et al. Short-term effect of cocoa product consumption on lipid profile: a meta-analysis of randomized controlled trials. Am J Clin Nutr 2010;92:218-25.

30 Mursu J, Voutilainen S, Nurmi T, Rissanen TH, Virtanen JK, Kaikkonen J, et al. Dark chocolate consumption increases HDL cholesterol concentration and chocolate fatty acids may inhibit lipid peroxidation in healthy humans. Free Radic Biol Med 2004;37:1351-9.

31 Grassi D, Necozione S, Lippi C, Croce G, Valeri L, Pasqualetti P, et al. Cocoa reduces blood pressure and insulin resistance and improves endothelium-dependent vasodilation in hypertensives. Hypertension 2005;46:398-405.

32 Steinberg FM, Bearden MM, Keen CL. Cocoa and chocolate flavanoids: implications for cardiovascular health. J Am Diet Assoc 2003;103:215-23.

33 Katz DL, Doughty K, Ali A. Cocoa and chocolate in human health and disease. Antioxid Redox Signal 2011;15:2779-811.

34 Field DT, Williams CM, Butler LT. Consumption of cocoa flavanols results in an acute improvement in visual and cognitive functions. Physiol Behav 2011:103.255-60.

35 Macht M, Dettmer D. Everday mood and emotions after eating a chocolate bar or an apple. Appetite 2006;46:332-6.

36 Ried K, Frank OR, Stocks NP. Dark chocolate or tomato extract for prehypertension: a randomised controlled trial. BMC Complement Altern Med 2009;9:22.

37 Taubert D, Berkels R, Roesen R, Klaus W. Chocolate and blood pressure in elderly individuals with isolated systolic hypertension. JAMA 2003,290:1029-30.

38 Grassi D, Desideri G, Necozione S, Lippi C, Casale R, Properzi G, et al. Blood pressure is reduced and insulin insensitivity increased in glucose-intolerant, hypertensive subjects after 15 days of consuming high-polyphenol dark chocolate. J Nutr 2008;138:1671-6.

39 Muniyappa R, Hall G, Kolodziej TL, Karne RJ, Crandon SK, Quon MJ. Cocoa consumption for 2 wk enhances insulin-mediated vasodilatation without improving blood pressure or insulin resistance in essential hypertension. Am J Clin Nutr 2008:88:1685-96.

40 Balzer J, Rassaf T, Heiss C, Karne RJ, Crandon SK, Quon MJ. Sustained benefits in vascular function through flavanol-containing cocoa in medicated diabetic patients a double-masked, randomized, controlled trial. J Am Coll Cardiol 2008;51:2141-9.

Accepted: 17 April 2012

\section{Cite this as: BMJ 2012:344:e3657}

This is an open-access article distributed under the terms of the Creative Commons Attribution Non-commercial License, which permits use, distribution, and reproduction in any medium, provided the original work is properly cited, the use is non commercial and is otherwise in compliance with the license. See: http://creativecommons.org/licenses/bync/2.0/ and http://creativecommons.org/licenses/by-nc/2.0/legalcode. 


\section{What is already known on this topic}

Dark chocolate has antihypertensive, anti-inflammatory, antithrombotic, and metabolic effects

Short term trials have shown that dark chocolate consumption can potentially reduce systolic blood pressure by $5 \mathrm{~mm} \mathrm{Hg}$ (interquartile range $2-8 \mathrm{~mm} \mathrm{Hg})$ and total cholesterol concentration by $0.21 \mathrm{mmol} / \mathrm{L}(0.05-0.36 \mathrm{mmol} / \mathrm{L})$

\section{What this study adds}

A modelling analysis predicted that dark chocolate consumption in populations at high risk of cardiovascular disease could potentially avert cardiovascular events over the long term owing to its antihypertensive and metabolic effects

The model also suggested that $\$ A 40$ ( $225 ; € 31 ; \$ 42$ ) could be cost effectively spent per person per year on prevention strategies using dark chocolate

This best case analysis suggests that dark chocolate/cocoa consumption with a polyphenol content of 500-1000 mg would be an effective and cost effective primary prevention strategy for those with multiple cardiovascular disease risk factors

\section{Tables}

\begin{tabular}{|c|c|c|c|c|}
\hline Study & Study design: therapy & Duration (days) & Dosage (g/d) & $\begin{array}{l}\text { Polyphenols per daily } \\
\text { dosage }(\mathrm{mg})\end{array}$ \\
\hline \multicolumn{5}{|c|}{$\begin{array}{l}\text { Systolic blood pressure effects in } \\
\text { hypertension trials: }\end{array}$} \\
\hline Taubert et $\mathrm{al}^{37}$ & Crossover: dark/white chocolate & 14 & 100 & 500 \\
\hline Grassi et al ${ }^{31}$ & Crossover: dark/white chocolate & 15 & 100 & 500 \\
\hline Taubert et al ${ }^{6}$ & Parallel: dark/white chocolate & 126 (18 weeks) & 6.3 & 30 \\
\hline Grassi et a $\left.\right|^{38}$ & Crossover: dark/white chocolate & 15 & 100 & 1008 \\
\hline Muniyappa et al ${ }^{39}$ & $\begin{array}{l}\text { Crossover: high flavonol cocoa/low flavonol } \\
\text { drink }\end{array}$ & 14 & 31 cocoa & 900 (control: 28) \\
\hline \multicolumn{5}{|c|}{$\begin{array}{l}\text { Cholesterol effects in cardiovascular } \\
\text { risk trials: }\end{array}$} \\
\hline Grassi et $\mathrm{al}^{31}$ & Crossover: dark/white chocolate & 15 & 100 & 88 \\
\hline Taubert et al ${ }^{6}$ & Parallel: dark/white chocolate & 126 (18 weeks) & 6.3 & 30 \\
\hline Balzer et a $\left.\right|^{40}$ & $\begin{array}{l}\text { Crossover: high flavonol cocoa/low flavonol } \\
\text { drink }\end{array}$ & 30 & 54 & 963 (control: 75) \\
\hline Muniyappa et al ${ }^{39}$ & $\begin{array}{l}\text { Crossover: high flavonol cocoa/low flavonol } \\
\text { drink }\end{array}$ & 14 & 31 cocoa & 900 (control: 28) \\
\hline
\end{tabular}

Only significant effects shown in meta-analyses were included in the model, therefore blood pressure effects were limited to those in people with hypertension and cholesterol effects to those at risk of cardiovascular disease (people with diabetes or hypertension, or both). 
Table 2| Data inputs used in Markov model of the effect and cost effectiveness of dark chocolate consumption in a population with metabolic syndrome free of cardiovascular disease and diagnosed diabetes

\begin{tabular}{|c|c|c|c|}
\hline Data input & Base case value & Uncertainty analysis & Sources \\
\hline Reduction in systolic blood pressure $(\mathrm{mm} \mathrm{Hg})$ & 5 & 2 to 8 & Ried $2010^{9}$ \\
\hline Reduction in total cholesterol (mmol/L) & 0.21 & 0.05 to 0.36 & Jia $2010^{11}$ \\
\hline \multicolumn{4}{|l|}{ Annual cost data $(\$ A)$} \\
\hline \multicolumn{4}{|l|}{ Myocardial infarction: } \\
\hline Year 1 care & 23588 & 21229 to 25947 & Salkeld $1997^{19}$ \\
\hline Ongoing care & 2321 & 2089 to 2553 & Salkeld $1997^{19}$ \\
\hline \multicolumn{4}{|l|}{ Stroke: } \\
\hline Year 1 care & 27047 & 24342 to 29752 & Salkeld $1997^{19}$ \\
\hline Ongoing care & 6828 & 6145 to 7511 & Salkeld $1997^{19}$ \\
\hline Cardiovascular death & 14756 & 13280 to 16231 & Walker $2010^{20}$ \\
\hline
\end{tabular}

$\$ A 1.00(£ 0.62 ; € 0.77 ; \$ 0.99)$. 
Table 3| Baseline characteristics of modelled population ( $n=2013)$ : metabolic syndrome, free of cardiovascular disease or diabetes, prehypertensive/hypertensive, and not receiving any antihypertensive therapy from Australian Diabetes, Obesity and Lifestyle study. Values are means (standard deviations) unless stated otherwise

\begin{tabular}{lc} 
Population characteristics & Values \\
No (\%) men & $1104(54.8)$ \\
\hline No (\%) women & $909(45.2)$ \\
\hline Age (years) & $53.6(13.1)$ \\
\hline Systolic blood pressure $(\mathrm{mm} \mathrm{Hg})$ & $141.1(13.8)$ \\
\hline Total cholesterol $(\mathrm{mmol} / \mathrm{L})$ & $6.1(1.1)$ \\
\hline High density lipoprotein cholesterol $(\mathrm{mmol} / \mathrm{L})$ & $1.2(0.3)$ \\
\hline HbA ${ }_{1 \mathrm{c}}(\mathrm{mmol} / \mathrm{mol})$ & $34.3(6.4)$ \\
\hline Waist circumference $(\mathrm{cm})$ & $100.4(11.4)$ \\
\hline Body mass index $\left(\mathrm{kg} / \mathrm{m}^{2}\right)$ & $29.9(4.8)$ \\
\hline Smoking $(\%)$ & $260(13.0)$ \\
\hline Parental history of diabetes $(\%)$ & $408(20.3)$ \\
\hline
\end{tabular}


Table 4| Base case and sensitivity analysis results in a Markov model of effectiveness and cost effectiveness ${ }^{\star}$ of dark chocolate consumption according to compliance levels versus no dark chocolate consumption over 10 years in prehypertensive/hypertensive people with metabolic syndrome, free of cardiovascular disease and diagnosed diabetes. Values are base cases (interquartile ranges)

\begin{tabular}{|c|c|c|c|c|c|}
\hline \multirow[b]{2}{*}{ Compliance level } & \multicolumn{2}{|c|}{ Cardiovascular events prevented/10 000 population } & \multirow[b]{2}{*}{ Years of life saved } & \multicolumn{2}{|c|}{ Monies available annually per person } \\
\hline & Non-fatal & Fatal & & $\$ A$ & $\$$ \\
\hline $100 \%$ compliance & $70(55-85)$ & $15(5-20)$ & $40(15-60)$ & $40(29-55)$ & $42(31-58)$ \\
\hline $90 \%$ compliance & $60(50-80)$ & $10(5-20)$ & $35(5-55)$ & $37(26-51)$ & $39(27-54)$ \\
\hline $80 \%$ compliance & $55(40-70)$ & $10(5-15)$ & $30(10-50)$ & $32(22-45)$ & $34(23-47)$ \\
\hline
\end{tabular}

*Defined by potential monies available for it to be considered cost effective.

$\$ A 1.00$ (£0.62; €0.77; \$0.99). 


\section{Figure}

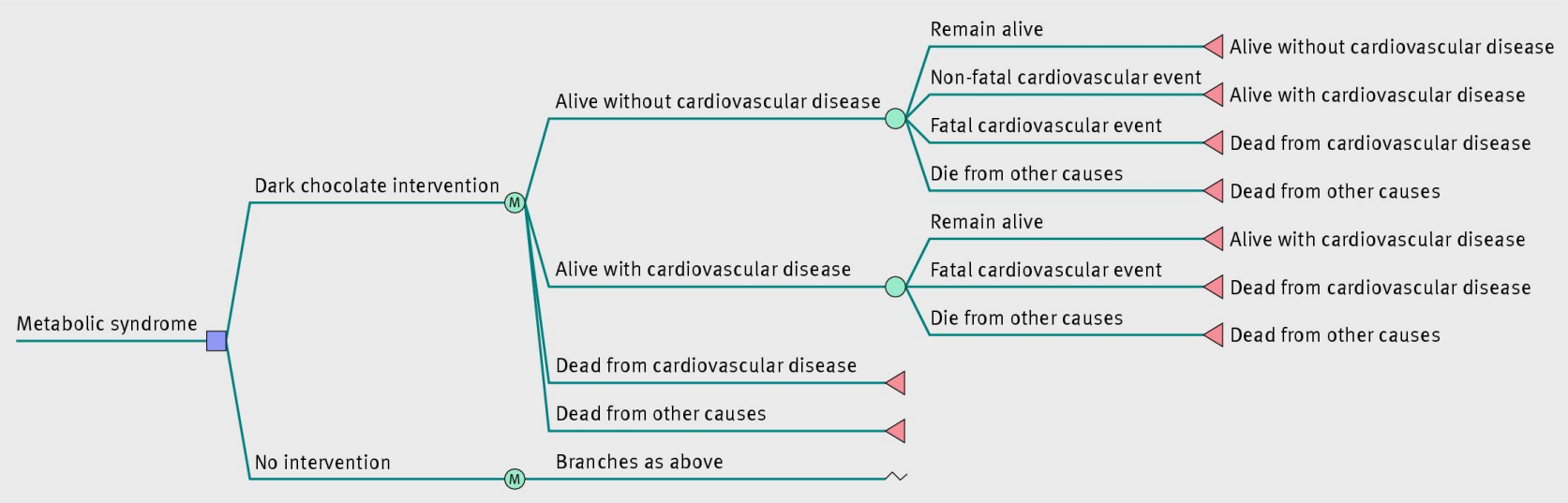

Markov model of effect of dark chocolate consumption versus no consumption and its effects on cardiovascular outcomes in a population with metabolic syndrome 